\title{
A Cross-Sectional Study on the Prevalence of Footpad Dermatitis in Canadian Turkeys
}

\author{
Emily M. Leishman ${ }^{1}$, Nienke van Staaveren ${ }^{1,2}$, Vern R. Osborne ${ }^{1,3}$, Benjamin J. Wood ${ }^{1,4,5}$, \\ Christine F. Baes ${ }^{1,6 *}$ and Alexandra Harlander-Matauschek ${ }^{2 \dagger}$
}

${ }^{1}$ Centre for the Genetic Improvement of Livestock, Department of Animal Biosciences, University of Guelph, Guelph, ON, Canada, ${ }^{2}$ Campbell Centre for the Study of Animal Welfare, Department of Animal Biosciences, University of Guelph, Guelph, ON, Canada, ${ }^{3}$ Centre for Nutrition Modelling, Department of Animal Biosciences, University of Guelph, Guelph, ON, Canada, ${ }^{4}$ Hybrid Turkeys, Kitchener, ON, Canada, ${ }^{5}$ School of Veterinary Science, University of Queensland, Gatton, QLD, Australia, ${ }^{6}$ Institute of Genetics, Vetsuisse Faculty, University of Bern, Bern, Switzerland

OPEN ACCESS

Edited by:

Marisa Erasmus,

Purdue University, United States

Reviewed by:

Jesse L. Grimes,

North Carolina State University,

United States

Sally Noll,

University of Minnesota Twin Cities,

United States

*Correspondence:

Christine F. Baes

cbaes@uoguelph.ca

tThese authors have contributed equally to this work and share last authorship

Specialty section:

This article was submitted to Animal Physiology and Management, a section of the journal

Frontiers in Animal Science

Received: 17 June 2021

Accepted: 23 August 2021

Published: 21 September 2021

Citation:

Leishman EM, van Staaveren N, Osborne VR, Wood BJ, Baes CF and Harlander-Matauschek A (2021) A

Cross-Sectional Study on the Prevalence of Footpad Dermatitis in Canadian Turkeys.

Front. Anim. Sci. 2:726907. doi: 10.3389/fanim.2021.726907
Footpad dermatitis (FPD) can be a prevalent issue in commercial turkey production. This study aimed to identify the bird, housing, and management-related factors associated with the prevalence of FPD in the Canadian turkey flocks. A questionnaire and flock health scoring system were developed and disseminated to $~ 500$ commercial turkey farmers across Canada. Farmers were asked to score FPD on a subset of 30 birds within their flock using a 0-2 scoring scale based on severity. The prevalence of FPD in the flock was calculated as the percentage of affected birds (score 1 or 2). A multivariate linear regression modeling was used to identify the factors associated with the prevalence of FPD. Four variables were included in the final model and accounted for $26.7 \%$ of the variation in FPD prevalence among the flocks. FPD prevalence was higher with increasing bird weight (3.6 \pm 1.13$)$, higher in flocks bedded with straw (12.1 \pm 7.9$)$, higher in flocks where birds were picked up less frequently during daily inspections (11.6 \pm 8.10$)$, and higher in flocks that used feed/water additives to reduce litter moisture (20.5 \pm 10.59$)$. These findings are a preliminary exploratory assessment of risk factors related to FPD prevalence on Canadian turkey farms. While these findings emphasize the importance of litter management and the stockperson, estimates and $P$-values from this study should be interpreted with caution. Further, longitudinal studies with the identified variables are required to better determine their influence on FPD.

Keywords: pododermatitis, footpad lesions, risk factors, management, stockmanship, animal well-being and welfare, poultry

\section{INTRODUCTION}

Galliformes are bipedal and when bipedal animals walk, one foot supports the body stance, while the other foot facilitates the forward movement (Muir et al., 1996). This movement pattern stresses the importance of foot health during locomotion. When normal standing and walking are disrupted by a foot health problem, such as a disease (acute or chronic), disorder, trauma, or injury, the body function will suffer (Hawke and Burns, 2009).

Footpad health can decline in commercial (Erasmus, 2017a) and organic (Freihold et al., 2019) turkey production systems. Lesions on the plantar area and the metatarsal footpads start as broken epidermis/skin (Shepherd and Fairchild, 2010). These issues can start 
in as early as the first of life and serve as a starting point for local inflammation (dermatitis), which can develop into ulcers, and potentially secondary bacterial infections and lameness (Clark et al., 2002; Erasmus, 2017b) throughout the growing period in male and female turkeys (e.g., 11-17 weeks of age in Canada).

A foot health issue of particular importance in turkey production is footpad dermatitis (FPD). The footpads become swollen, discolored, and hard (Sinclair et al., 2015). As early as 6 weeks of age, diagnosable FPD can be common in a flock (Mitterer-Istyagin et al., 2011). At slaughter, it can be common for birds in commercial (Ekstrand and Algers, 1997; KrautwaldJunghanns et al., 2011; Allain et al., 2013; Da Costa et al., 2014) and organic (Hocking and $\mathrm{Wu}, 2013$ ) flocks to have varying degrees of FPD. As bipedal turkeys need both feet to stand and walk, and FPD tends to affect both feet with the same severity (Ekstrand and Algers, 1997), it is likely, not easy to favor one limb to avoid potential discomfort and pain due to inflammation or alleviate impaired function (Martland, 1984; Ekstrand and Algers, 1997; Hocking and Wu, 2013; Weber Wyneken et al., 2015).

Given the evidence that FPD is painful (Martland, 1984; Hocking and Wu, 2013; Sinclair et al., 2015; Weber Wyneken et al., 2015), it is used as an animal welfare indicator in research, on farms, and in slaughterhouses (Watanabe et al., 2013). To illustrate the importance of FPD, United Kingdom supermarkets have identified FPD as a key welfare indicator in turkeys (Clark et al., 2002), and most animal welfare audits in Europe and the United States consider FPD an indicator of impaired welfare (Berg, 2004; Berg and Algers, 2004). In Canada, producers are provided with background information about FPD as it relates to litter quality and stocking density, but there is no formal assessment or auditing of FPD at this time (Turkey Farmers of Canada, 2018). In addition to the implications for animal wellbeing, FPD is a key issue for food safety, farm productivity, and financial profitability (Shepherd and Fairchild, 2010). Moreover, to reduce pain, turkeys affected by FPD are less active and exhibit less variation in their behavior patterns (Martland, 1984; Hocking and Wu, 2013; Weber Wyneken et al., 2015). This may result in a lower feed intake, which ultimately reduces growth rate and body weight and increases contact time with the litter, which has implications for further contact dermatitis and increased mortality (Martland, 1984; Mayne et al., 2007).

The etiology of FPD is known to be multifactorial (Shepherd and Fairchild, 2010). Predisposing factors, such as genetics, bird age and body weight, diet and excreta composition, bedding material, and management have been identified as the main contributing factors as birds stand, rest, and walk-in floor barns at stocking densities that allow the floor (and any bedding on it) to quickly accrue with feathers, waste feed, and excreta (Monckton et al., 2020). However, reported on-farm FPD assessments of turkeys are typically from Europe, where genetic line, housing, and management practices can differ compared with North America (Martrenchar et al., 2002; KrautwaldJunghanns et al., 2013). Currently, investigations of risk factors associated with the prevalence of FPD in North American turkey production systems are lacking. Therefore, this study aimed to identify the bird, housing, and management characteristics associated with the prevalence and severity of FPD on Canadian turkey farms.

\section{MATERIALS AND METHODS}

This study was part of a larger cross-sectional study to describe the housing and management practices of commercial turkeys in Canada (van Staaveren et al., 2020), and identify housing and management risk factors for FPD and pecking injuries. In brief, farmers were asked to 1) complete a questionnaire about their housing and management practices for a turkey flock on their farm and 2) perform simplified health scoring on a random subset of 30 turkeys in their flock. The data from both the questionnaire and health scoring were then used to identify the practices associated with FPD using regression modeling. The present study reports the prevalence of FPD and related risk factors on Canadian farms.

TABLE 1 | A summary of the housing and management information on Canadian turkey flocks obtained from the survey questionnaire.

\begin{tabular}{|c|c|}
\hline Background information & $\begin{array}{l}\text { Farmer demographics } \\
\text { Farmer experience } \\
\text { Farm size and production } \\
\text { Veterinary relationship }\end{array}$ \\
\hline Flock characteristics & $\begin{array}{l}\text { Flock sex, strain, age, average weight } \\
\text { Physical alterations } \\
\text { Stocking density } \\
\text { Flock certifications (i.e., RWAa) }\end{array}$ \\
\hline Flock housing & $\begin{array}{l}\text { Housing system } \\
\text { Flooring } \\
\text { Enrichment }\end{array}$ \\
\hline Lighting & $\begin{array}{l}\text { Lighting type, intensity, evenness } \\
\text { Dark period (length, intermittent lighting) }\end{array}$ \\
\hline Air quality & $\begin{array}{l}\text { Ventilation type } \\
\text { Ventilation rate } \\
\text { Target temperature and humidity } \\
\text { Ammonia and dust }\end{array}$ \\
\hline Litter management & $\begin{array}{l}\text { Litter type, depth, condition } \\
\text { Practices for maintaining litter quality } \\
\text { Reuse of litter } \\
\text { Litter products }\end{array}$ \\
\hline Feeding & $\begin{array}{l}\text { Feed structure } \\
\text { Diet changes } \\
\text { Feed source } \\
\text { Feed supplements } \\
\text { Animal by-products }\end{array}$ \\
\hline Watering & $\begin{array}{l}\text { Drinker type } \\
\text { Water source } \\
\text { Water sanitizing products } \\
\text { Water supplements } \\
\text { Water quality } \\
\text { Flock water consumption }\end{array}$ \\
\hline Flock health & $\begin{array}{l}\text { Barn cleaning } \\
\text { Biosecurity practices } \\
\text { Flock inspections } \\
\text { Vaccines and medications } \\
\text { Flock diseases } \\
\text { Mortality and culling }\end{array}$ \\
\hline
\end{tabular}

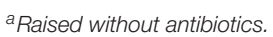




\section{Survey Design}

The survey to identify risk factors for FPD contained two main components such as a questionnaire and an FPD scoring guide. The questionnaire consisted mainly of (semi-) closed questions and covered sections on general farm information and experience, housing (i.e., lighting, air quality), litter management, feed and water management, flock health and biosecurity, and farmer perceptions. The farmers were asked to fill in the questionnaire for a flock of birds currently on their farm. A more detailed breakdown of the questionnaire sections and subsections can be found in Table 1. The questionnaire was tested by industry collaborators and was estimated to take $\sim 1-1.5 \mathrm{~h}$ to complete. The questionnaire was further reviewed by the members of the national organization representing turkey farmers of Canada, the Turkey Farmers of Canada (TFC), poultry veterinarians, feed sales representatives, and turkey farmers to ensure the questions and wording were understandable and accurately reflected the commercial settings.

The FPD scoring guide was designed in collaboration with the industry stakeholders to ensure that it was feasible to complete in a commercial turkey production setting. The scoring guide was used by farmers to assess FPD in the flock corresponding with the information from the questionnaire. FPD was scored by each farmer on a random subset of 30 birds in their flock on a 3-point scale according to the severity of the condition based on visual (Figure 1) and written (Table 2) descriptions, adapted

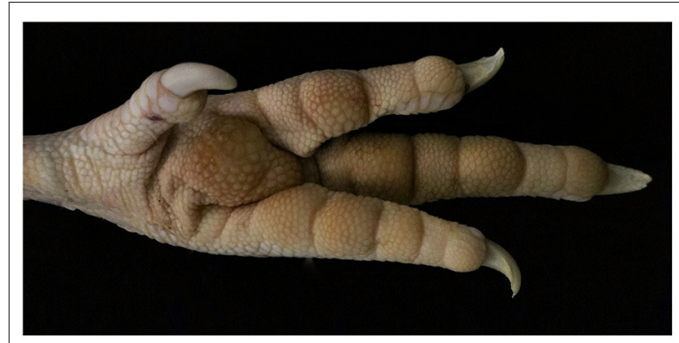

Score 0

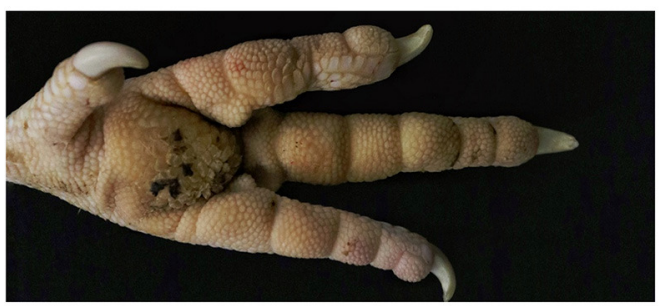

Score 1

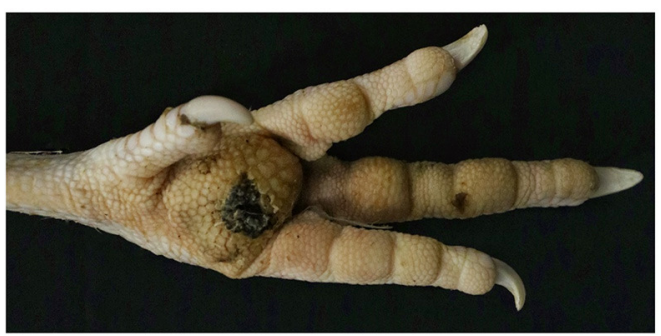

FIGURE 1 | Photographs of foot lesions from turkeys at slaughter used as visual descriptions in the footpad dermatitis (FPD) scoring system. from Knierim et al. (2016). The proportion of the footpad affected by FPD was used to differentiate between lesion scores (i.e., in the most severe category, more than half of the footpad is affected; Knierim et al., 2016). The footpad images used in the visual aid were obtained from cleaned turkey feet at slaughter. To try and account for the cleanliness of the scoring images, farmers were asked to lightly brush any loose litter that might obscure FPD lesions from the footpad before scoring. If the two footpads of a bird differed in severity, the farmers were instructed to record the more severe of the two scores. Farmers did not receive any formal training on the scoring system, but they were given visual and written instructions for selecting a random sample of birds and conducting the scoring of the footpads.

\section{Survey Distribution}

The turkey farmers across Canada were invited to participate in the survey through the TFC in April 2019. Each farmer received a package containing a cover letter, questionnaire, health scoring guide with instructions, and return envelope with a unique code to collect all responses anonymously. All documents were made available in English and French. Additionally, farmers were provided the opportunity to fill in the questionnaire online via Qualtrics ${ }^{\circledR}$ (Qualtrics, Provo, UT, USA). The reminders were sent out through the TFC until the end of data collection in December 2019. As an incentive and thanks for participating, farmers received a $\$ 10 \mathrm{CAD}$ gift card for a popular Canadian coffee franchise. This study was approved by the University of Guelph Research Ethics Board (REB 19-02-015) and the University of Guelph Animal Care Committee (AUP 3782), Ontario, Canada.

\section{Statistical Methods}

Due to the lower number of birds with an FPD score of 2 (most severe) (Table 3), the flock-level prevalence of FPD for analysis was estimated as the percentage of birds in a flock with a score $>0$. Data obtained from the questionnaires were used to determine potential factors associated with FPD prevalence in a flock. The statistical analyses were performed in RStudio (version 3.5.3., R Core Team, Vienna, Austria, 2019).

TABLE 2 | Simplified scoring system for farmers to score footpad dermatitis (FPD) on a subset of 30 turkeys in their flock.

\begin{tabular}{ll}
\hline Score & Footpad condition \\
\hline 0 & No signs of footpad dermatitis \\
Intact, soft skin without swelling or necrotic areas \\
Litter can be brushed off footpad easily \\
Hard or dense skin \\
Small necrotic areas on $<25 \%$ of the footpad \\
Litter cannot be removed easily from footpad \\
Large necrotic areas and/or swelling on $>25 \%$ of the \\
footpad \\
Litter adhered to footpad and cannot be removed easily
\end{tabular}


TABLE 3 | Descriptive characteristics of 63 commercial turkey flocks were used in this analysis.

\begin{tabular}{|c|c|c|c|}
\hline & $\mathbf{N}^{\mathrm{a}}$ & Mean (SD) & Median (IQR) \\
\hline Flock age (wks) ${ }^{b}$ & 63 & & \\
\hline Toms & 24 & $11(3)$ & 12 (IQR: 10 - 14) \\
\hline Hens & 39 & $11(7)$ & 9 (IQR: 7 - 12) \\
\hline Average bird weight $(\mathrm{kg})^{\mathrm{c}}$ & 63 & & \\
\hline Toms & 24 & $9(3)$ & 9 (IQR: 7 - 11) \\
\hline Hens & 39 & $6(3)$ & 5 (IQR: $4-8)$ \\
\hline Flock size $^{d}$ & 63 & & \\
\hline Toms & 24 & $5,885(4,282)$ & 4,350 (IQR: 2,198 - 10,450) \\
\hline Hens & 39 & $8,030(5,063)$ & 7,380 (IQR: 4,560 - 11,284) \\
\hline \multicolumn{4}{|l|}{ FPD prevalence (\%)e } \\
\hline Score 0 & 1,175 & $62(34)$ & 73 (IQR: 33 - 90) \\
\hline Score 1 & 539 & $29(25)$ & 20 (IQR: 7 - 47) \\
\hline Score 2 & 176 & $9(20)$ & 0 (IQR: 0 - 10) \\
\hline Score $1+$ Score 2 & 715 & $38(34)$ & 27 (IQR: $10-67)$ \\
\hline
\end{tabular}

Data are presented as the mean $\pm S D$ and the median with associated interquartile range (IQR).

${ }^{a}$ Number of flocks (age, weight, and flock size) or the number of birds (FPD prevalence only).

${ }^{b}$ Age of the flock in weeks at the time of survey completion.

${ }^{c}$ Average weight of an individual bird in the flock in kilogram at the time of survey completion.

${ }^{d}$ Size of the flock in the number of birds at the time of survey completion.

e Flock level prevalence of the different FPD severity scores from the 63 surveyed flocks.

\section{Model Building}

Data collected from the questionnaire were entered into Excel using manual double entry and checked for errors. The variables with many missing values or insufficient variation (e.g., a binary variable with a proportion of responses approximately $>0.85$ in one category) were excluded from the further investigation (Decina et al., 2019). Some variables underwent retrospective collapsing of categories to remove the unused or infrequent categories. After this screening, a total of 19 variables remained and progressed to the univariate analysis.

In the univariate analysis, variables that had a $p \leq 0.25$ or were considered biologically relevant were retained for further analysis. This $P$-value was chosen based on similar poultry risk factor analysis for feather damage (Decina et al., 2019) and FPD (Martrenchar et al., 2002). The variables were tested for collinearity using Pearson correlations. Strong correlations $(r>$ 0.5 ) were considered to indicate redundant variables, and only one of these variables was retained in the multivariate analysis. To illustrate, the flock age was highly correlated with flock weight, stocking density, and target temperature. We chose flock weight to be retained in the multivariate analysis because bird weight has important biological implications for FPD development (Tullo et al., 2017). After assessing collinearity, 16 predictor variables were included in the multivariate analysis using a mixed linear regression model with a forward selection approach. The variables that were significant $(P \leq 0.05)$ and/or contributed to a higher adjusted $R^{2}$ were included in the final model. Relevant interactions among the included predictor variables were also tested.

Model diagnostics to assess the normality of the residuals were conducted using a QQ-plot. The homogeneity of variance was graphically evaluated using a scatterplot of the studentized residuals against the predicted values. Collinearity was assessed using the variance inflation factor (VIF). The outliers were identified using a boxplot of the model residuals, and Cook's distance was used to investigate the influential data points.

\section{RESULTS}

\section{Response Rate}

In this study, 500 surveys were sent to turkey farmers across the country. The response rate was $\sim 20 \%$ (101 responses). Of the 101 responses, 66 were completed surveys with scoring (13.2\%), and 35 were incomplete $(7.0 \%)$ where the respondents indicated that they are not currently producing turkeys or did not complete the scoring portion of the survey. Three surveys were excluded from the analysis due to incorrect interpretation of the instructions, which left 63 surveys to be used in the risk factor analysis.

\section{General Flock Information}

Of the flocks included in the risk factor analysis, 39 were hen flocks (61.9\%), and 24 flocks were tom flocks (38.1\%). The FPD prevalence (score $>0$ ) for the surveyed flocks is shown in Figure 2.

The information on flock age, bird weight, flock size, and FPD prevalence can be found in Table 3. A detailed description of the flocks included in this study and their housing and management practices can be found in van Staaveren et al. (2020).

\section{Univariate Analysis of Factors Associated With FPD}

The variables associated at a liberal significance level $(\alpha=0.25)$ or biologically relevant to FPD at the univariate analysis level are presented in Table 4 . These variables were related to the 


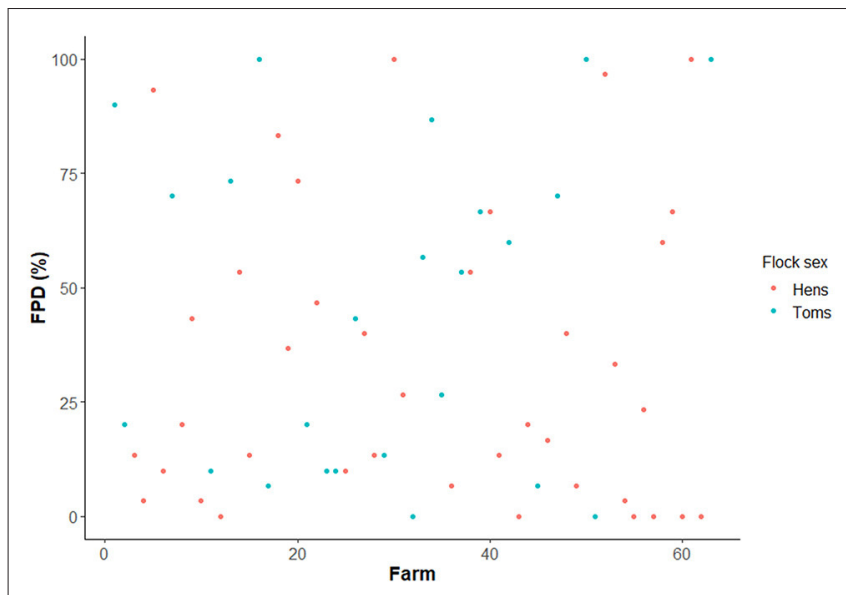

FIGURE 2 | Percentage of birds affected with FPD (score > 0) in the scored subsets of the surveyed flocks ( $\mathrm{N}_{\text {Flocks }}=63$ ).

bird characteristics, such as sex, physical alterations, age, and weight. There were also several variables related to litter and litter management (e.g., litter type, litter tilling, and adding dry bedding) and housing (e.g., housing system and drinker type).

\section{Multivariate Analysis of Factors Associated With FPD}

Average bird weight, litter type, picking up birds during inspections, and feed/water additives were included in the final model and accounted for $26.7 \%$ of the variation in FPD prevalence among flocks (Table 5). Increasing average weight was associated with an increased prevalence of FPD. Additionally, the use of straw (vs. wood shavings) and not picking up birds during routine inspections tended to be associated with a higher prevalence of FPD. Interestingly, in flocks where feed/water additives were used to reduce litter moisture, the prevalence of FPD tended to be higher than those that did not use additives.

\section{DISCUSSION}

Footpad dermatitis is a well-known health and welfare issue of turkey (Shepherd and Fairchild, 2010). WWhen not treated through appropriate management, it can lead to FPD affecting almost $100 \%$ of birds to some degree on one or both feet, (Allain et al., 2013; Krautwald-Junghanns et al., 2013; Da Costa et al., 2014), making movement potentially uncomfortable, irritating, or even painful (Sinclair et al., 2015; Weber Wyneken et al., 2015). However, there is relatively little published information on the severity and prevalence of FPD in turkeys in North America (Da Costa et al., 2014; Erasmus, 2017b) even though North America is a major contributor to the global turkey industry (Windhorst, 2006). To add information to the North American prevalence of FPD in turkeys, we conducted a survey on housing and management factors associated with FPD in turkey flocks in Canada using farmer self-reported FPD scores.
The median prevalence of FPD across both tom and hen flocks was 27\% [interquartile range (IQR): 10-67\%] across 63 flocks. This is lower than the prevalence of FPD reported in other studies, however, this could be due to the reason that these studies are typically being conducted at slaughter (Ekstrand et al., 1997; Krautwald-Junghanns et al., 2011; Allain et al., 2013; Da Costa et al., 2014). The factors most strongly associated with FPD were increasing bird weight, using straw litter, infrequently picking up birds during inspections, and using feed or water additives to reduce litter moisture.

The current study involved both hen and tom flocks reared for different median target weights (hens: $6.5 \mathrm{~kg}$, toms: $16.0 \mathrm{~kg}$, van Staaveren et al., 2020). It is well-established that the prevalence and severity of FPD increase with both bird age and weight. This is understandable as birds gain weight as they get older $(r=0.92$ in the current study), and so to avoid issues with collinearity, weight was included in the model as a biological consequence of both flock sex and age. Using bird weight instead of age also improved the adjusted $R^{2}$ of the model, which reinforced our choice.

Flock sex passed the univariate stage $(p=0.15)$ but was not included in the final multivariate model. At the univariate level, tom flocks were found to have a higher FPD prevalence than hen flocks (estimate: $+12.5 \pm 8.66 \%$ ). This can be expected in North America since toms are grown at a higher per weight density (National Farm Animal Care Council, 2016), and so these larger birds consume more feed and water. This results in more excreta (and more watery) potentially leading to worse litter quality which is a factor in the development of FPD (Youssef et al., 2011). It is also possible that we found a higher prevalence in tom flocks due to the cross-sectional nature of this study and the lack of restriction placed on the flock age to make the study as inclusive as possible. The hen flocks that were surveyed had a younger median age ( 9 weeks) and a lighter median weight $(5 \mathrm{~kg})$ than tom flocks (12 weeks and $9 \mathrm{~kg}$, respectively). The pressure exerted by heavier birds on the footpads increases contact with excreta-soiled litter (Shepherd and Fairchild, 2010). Since our surveyed tom flocks were older and heavier, this may have contributed to the higher observed prevalence.

In poultry studies, the influence of sex on FPD is largely inconclusive because of the inconsistent results which may suggest that sex is not an important contributor to FPD prevalence (Shepherd and Fairchild, 2010). Several European studies of turkey FPD prevalence demonstrate that hens are typically more severely affected than toms (Martrenchar et al., 2002; Krautwald-Junghanns et al., 2011; Bergmann et al., 2013). However, the rearing conditions (e.g., mixed-sex flocks) and other management decisions (e.g., diet and strain) are different in European systems compared to North America. For example, wheat-based diets are more commonly used in Europe compared with North America which is dominated by corn-soybean based diets (Wood and Willems, 2014). Wheat-based diets have a larger non-starch polysaccharide component that decreases digestibility and increases water intake, and consequently excretion which may influence the development of FPD (Patterson et al., 1989; Wood and Willems, 2014). So, there may be other underlying 
TABLE 4 | Explanatory variables ( $p \leq 0.25$ or biologically relevant) associated with FDP in turkeys at the univariate analysis level.

\begin{tabular}{|c|c|c|c|}
\hline Variable & $N(\%)$ & Estimate (SE) & $P$-value \\
\hline Flock sex & & & 0.1548 \\
\hline Hens & $39(61.9)$ & Referent & \\
\hline Toe trimming & & & 0.09163 \\
\hline No & $29(47.5)$ & Referent & \\
\hline No & $47(76.7)$ & Referent & \\
\hline Yes & $14(23.3)$ & $-22.477(10.016)$ & \\
\hline Growing system & & & 0.6214 \\
\hline Brood and move & $45(75.0)$ & Referent & \\
\hline Brood to finish & $15(25.0)$ & $5.037(10.145)$ & \\
\hline Housing system & & & 0.2796 \\
\hline Power & $41(66.1)$ & Referent & \\
\hline Natural & $21(33.9)$ & $-9.752(8.938)$ & \\
\hline Target temperature $\left({ }^{\circ} \mathrm{C}\right)$ & $63(100.0)$ & $-1.9320(0.7705)$ & 0.01493 \\
\hline Litter type & & & 0.1717 \\
\hline Wood shavings & $34(54.0)$ & Referent & \\
\hline Straw & $29(46.0)$ & $11.687(8.451)$ & \\
\hline Number of methods to check litter quality & $63(100.0)$ & $-7.444(4.834)$ & 0.1288 \\
\hline Adding dry bedding & & & 0.1641 \\
\hline No & $10(16.4)$ & Referent & \\
\hline Yes & $51(83.6)$ & $16.33(11.590)$ & \\
\hline Yes & $10(16.4)$ & Referent & \\
\hline No & $51(83.6)$ & $-25.82(11.300)$ & \\
\hline Feed supplements (e.g., vitamins, grit) & & & 0.1988 \\
\hline Yes & $30(52.6)$ & Referent & \\
\hline No & $27(47.4)$ & $-11.64(8.95)$ & \\
\hline Drinker type & & & 0.9130 \\
\hline Closed & $44(71.0)$ & Referent & \\
\hline Open & $18(29.0)$ & $1.044(9.510)$ & \\
\hline Picking up birds during inspections & & & 0.1075 \\
\hline Half the time or more & $28(45.2)$ & Referent & \\
\hline Never/sometimes & $34(54.8)$ & $13.936(8.528)$ & \\
\hline Cumulative mortality rate (\%) & $63(100.0)$ & $3.836(1.574)$ & 0.01795 \\
\hline
\end{tabular}

$N$ represents the number of flocks where a response was provided.

factors that make comparisons difficult between North America and Europe.

In tom flocks, a positive correlation (0.22) between body weight gain and severity of FPD has been reported (Da Costa et al., 2014). Similarly, we found that a $1 \mathrm{~kg}$ increase in average body weight was associated with a $3.6 \%$ higher prevalence of FPD, regardless of the sex of the flock. The heavier birds are typically older and have spent more time on the litter which can 
TABLE 5 | Final multivariate linear regression model for FPD prevalence in turkey flocks in Canada (alpha $=0.05$, adjusted $R^{2}=0.2148, p=0.003347, N_{\text {Flock }}=60$ ).

\begin{tabular}{|c|c|c|c|}
\hline Variable & Estimate & Standard Error & $P$-value \\
\hline Intercept & 18.881 & 14.839 & 0.20851 \\
\hline Flock weight (kg) & 3.584 & 1.133 & 0.002239 \\
\hline Litter type & & & 0.075398 \\
\hline Wood shavings & Referent & & \\
\hline Straw & 12.136 & 7.924 & \\
\hline Picking up birds during inspection & & & 0.082570 \\
\hline Half the time or more & Referent & & \\
\hline Never/sometimes & 11.590 & 8.099 & \\
\hline Feed/water additives to reduce litter moisture & & & 0.058101 \\
\hline Yes & Referent & & \\
\hline No & -20.488 & 10.591 & \\
\hline
\end{tabular}

play a large role in the development of FPD (Tullo et al., 2017). However, FPD lesions can heal over time in the appropriate environmental conditions (15 days for complete healing; Mayne et al., 2007), which may lead to a reduced prevalence/severity of FPD in birds with longer growing periods. Toms have a longer growing period than hens so they may have more time for lesions to heal which may explain some of the inconsistencies with regards to the effect of sex on FPD as it is confounded with other productions factors. The interconnections between flock sex, age, and weight are difficult to disentangle and have further connections to important management aspects, such as growing period, feed composition, geographic area, and litter quality.

The quality of stockmanship has an undeniable connection with animal welfare (Rushen and Passillé, 1992), but this aspect has received little attention in poultry farming. We found that the farmers who picked up their birds more frequently during inspections have a lower prevalence of FPD compared with the farmers who pick up birds less frequently. The effort put into picking up birds during most or all inspections can speak to the stockmanship of the farmer and indicate a conscious effort on the part of the farmer to address the FPD issues. Good stockmanship has been shown to be crucial for broiler welfare and can be even more influential than the factors, such as stocking density (Dawkins et al., 2004). This could explain why De Jong et al. (2012) found that the farmers had a relatively significant contribution in explaining FPD in broilers compared with e.g., hatchery, veterinary practice, or feed manufacturer. Furthermore, it is essential to realize that farmers as primary caretakers are responsible for the main decisions that influence the aspects of production, such as stocking density, litter management, and nutrition that all can influence FPD. This is especially important because of the seasonal changes in North America. Drying out the litter is more difficult during the winter seasons because of reduced ventilation but this problem can be reduced with good management. Further research should identify and quantify which specific attributes of stockmanship can positively impact turkey welfare to improve the conditions for both farm staff and birds.

Management of litter quality is one of the most frequently mentioned aspects to control FPD (Shepherd and Fairchild,
2010). Due to the nature of the study, it was not possible to take detailed litter quality measures; however, it should be noted that the majority of farmers indicated that, at the time of the survey, the litter was in good condition (i.e., not very dry/dusty nor damp/wet). There have also been many investigations into different litter types and textures and how they influence the development of FPD (Mayne, 2005; Shepherd and Fairchild, 2010). We found that the flocks housed in barns that were bedded with straw had a higher prevalence of FPD compared with those that did not use a straw. In the literature, straw bedding is associated with more severe FPD than wood shavings (Ekstrand and Algers, 1997; Mayne et al., 2007; Terčič et al., 2015). As suggested by Mayne et al. (2007), straw may perform worse than materials like wood shavings due to its higher moisture content. This effect was also demonstrated by Terčič et al. (2015), who found that straw litter had the highest moisture content (22\%) compared with wood shavings $(8 \%)$ and shredded paper (9\%). It should be noted that the litter materials will vary between the regions depending on cost and availability. In North America, straw bedding is still popular because it is more costeffective than wood shavings and is typically readily available, depending on the region (Hybrid Turkeys, 2020). The most common litter material reported in this study was wood shavings (54\%), which also is the most commonly used litter substrate in the United States, but can be subject to shortages, is more expensive, and produces more dust compared to some bedding types (Grimes et al., 2002; Hybrid Turkeys, 2020).

It is also worth considering the textural difference between straw and wood shavings. The particle size has been implicated as a contributing factor for FPD (Grimes et al., 2002). Large particle sizes make the litter more susceptible to caking, which can be a contributing factor for poultry dermatitis conditions (Grimes et al., 2002). Straw is typically a coarser material compared with wood shavings (Ward et al., 2000). Adding further evidence to the particle size argument, studies of broiler chickens have found that chopped straw results in significantly better leg health and FPD severity compared with unchopped straw (Đuki et al., 2016). A variety of questions related to litter management were included in the survey, but aspects, such as adding dry litter, adding heat, or tilling the litter did not contribute to the final model. We should 
note that these factors can still play a role in the prevalence of FPD and warrant further investigation.

One factor that did, however, contribute to the final model was the use of feed or water additives to reduce litter moisture. This question in the survey asked farmers specifically if they used additives to reduce litter moisture, as opposed to using additives for, e.g., performance, growth, or gut health, which was covered in a separate question. Surprisingly, using feed or water additives to reduce litter moisture tended to be associated with increased FPD prevalence. Using additives was associated with a $20 \%$ higher FPD prevalence compared with flocks where additives were not used. This finding is contrary to the previously reported effects where feed or water additives reduce litter moisture in poultry production, and so reduce the development of FPD (Mayne et al., 2007). Some limitations within our study could potentially explain this contradictory finding. First, we were unable to analyze the effect of specific additives or additives delivery methods (e.g., via feed or water) due to the small number of respondents who supplied this information $(N=11)$. The most frequently mentioned products included betaine, copper, citric acid, and essential oils (van Staaveren et al., 2020). Products, such as betaine and copper have been shown to impact water and ion balance (Saeed et al., 2017) or tissue integrity of the birds (Rucker et al., 1998). Consequently, these products can reduce litter moisture (Ferket, 1995) and positively impact the FPD scores when supplemented with poultry (Zhao et al., 2010; Manangi et al., 2012). Therefore, it was expected that the farmers who used these products in their flock would have lower levels of FPD due to benefits for litter quality and integument health. However, due to the cross-sectional nature of the study, we were unable to determine at what point the additives were introduced to the flock. It is possible that the additives to reduce litter moisture were applied to the flock as a response to FPD instead of a preventative technique-which also positively illustrates that the farmers are aware of the relationship between litter quality and footpad health. Furthermore, it may be due to the farms that have regular issues with FPD use these products, and so there may be other underlying characteristics of these farms influencing the prevalence that were not captured in this study. Additionally, the level of variation for this variable was close to our cut-off value ( $84 \%$ of respondents indicated they do not use additives), and so we may also be lacking some variation to make a proper assessment about this relationship.

This study was the first attempt to assess the factors associated with FPD on Canadian turkey farms. The main limitation that should be acknowledged is that, due to the exploratory nature of this study and the desire to include farms from the entire country, we relied on self-reported FPD scores from individual farmers. While the scoring system was simplified and based on the previous literature (Knierim et al., 2016), it was developed and pilot-tested with industry stakeholders. Each farmer received the same informational packet and scoring instructions; we cannot, however, completely rule out that there may have been differences among the farmers in how they scored their birds. Considering the variety in prevalence reported by the farmers, we believe that the instructions allowed farmers to capture the extent of FPD in their flocks. However, with the cross-sectional study design, this can only be considered as a snapshot of that specific flock in time, and the estimates and $P$-values presented in this study are exploratory. To truly determine the impact of the factors identified in this study, further longitudinal studies are required. This would also allow further investigation on FPD development over time and the potential management strategies in the future.

\section{CONCLUSION}

This study provided an exploratory assessment of FPD prevalence and risk factors using a survey of Canadian turkey flocks. The majority of FPD cases in the surveyed flocks were mild (score 1 , mean flock prevalence $=29 \%$ ), with a lesser percentage of birds severely affected (score 2 , mean flock prevalence $=9 \%$ ). The age of the flocks ranged from 10 to 14 weeks for toms and 712 weeks for hens. Overall, there was a median FPD prevalence (score $>0$ ) of 48 and $20 \%$ for tom and hen flocks, respectively. However, the range in prevalence was large for both tom (IQR: 10-72\%) and hen (IQR: 7-53\%) flocks suggesting a need for FPD management strategies to mitigate FPD. The analysis of factors related to FPD indicates that good stockmanship (picking up birds during inspections) and using wood shavings over straw bedding are associated with lower levels of FPD. The use of feed/water additives to reduce litter moisture and birds with heavier body weights was associated with the higher prevalence of FPD. However, in the case of cross-sectional studies, it is not possible to determine the cause and effect, and associations can be difficult to disentangle, so the results presented in this study should be interpreted with caution. The variables identified in this study would benefit from further longitudinal studies to investigate their impact on FPD in turkeys in more detail and develop management strategies to reduce FPD from an economic, societal, and animal welfare point of view.

\section{DATA AVAILABILITY STATEMENT}

The raw data supporting the conclusions of this article will be made available by the authors, without undue reservation.

\section{ETHICS STATEMENT}

The studies involving human participants were reviewed and approved by the University of Guelph Research Ethics Board REB\#:19-02-015. The patients/participants provided their written informed consent to participate in this study. The animal study was reviewed and approved by the University of Guelph Animal Care Committee (AUP 3782). Written informed consent was obtained from the owners for the participation of their animals in this study.

\section{AUTHOR CONTRIBUTIONS}

EL, NvS, VO, BW, AH-M, and $\mathrm{CB}$ conceived and designed the study, provided substantive input, and contributions to manuscript revision. EL and NvS conducted the study. 
EL analyzed the data and wrote the main manuscript. All the authors reviewed and approved the final manuscript.

\section{FUNDING}

This project was funded by the Government of Canada through Genome Canada and the Ontario Genomics Institute (OGI133). This study was part of the project entitled "Application of genomic selection in turkeys for health, welfare, efficiency and production traits" funded by the government of Canada through the Genome Canada Genomic Application Partnership Program and administered by Ontario Genomics [recipients: BW

\section{REFERENCES}

Allain, V., Huonnic, D., Rouina, M., and Michel, V. (2013). Prevalence of skin lesions in turkeys at slaughter. Br. Poult. Sci. 54, 33-41. doi: 10.1080/00071668.2013.764397

Berg, C. (2004). "Pododermatitis and hock burn in broiler chickens," in Measuring and Auditing Broiler Welfare, eds C. A. Weeks and A. Butterworth (Wallingford: CABI Pub), 37-49. doi: 10.1079/9780851998053. 0037

Berg, C., and Algers, B. (2004). "Using welfare outcomes to control intensification: the Swedish model," in Measuring and Auditing Broiler Welfare, eds A. Weeks and A. Butterworth (Wallingford: CABI Pub), 223-229. doi: 10.1079/9780851998053.0223

Bergmann, S., Ziegler, N., Bartels, T., Hübel, J., Schumacher, C., Rauch, E., et al. (2013). Prevalence and severity of foot pad alterations in German turkey poults during the early rearing phase. Poult. Sci. 92, 1171-1176. doi: $10.3382 / \mathrm{ps} .2012-02851$

Clark, S., Hansen, G., Mclean, P., Bond, P., Wakeman, W., Meadows, R., et al. (2002). Pododermatitis in turkeys. Avian Dis. 46, 1038-1044. doi: 10.1637/0005-2086(2002)046[1038:PIT]2.0.CO;2

Da Costa, M. J., Grimes, J. L., Oviedo-Rondón, E. O., Barasch, I., Evans, C., Dalmagro, M., et al. (2014). Footpad dermatitis severity on turkey flocks and correlations with locomotion, litter conditions, and body weight at market age. J. Appl. Poult. Res. 23, 268-279. doi: 10.3382/japr.2013-00 848

Dawkins, M. S., Donnelly, C. A., and Jones, T. A. (2004). Chicken welfare is influenced more by housing conditions than by stocking density. Nature. 427, 342-344. doi: 10.1038/nature02226

De Jong, I. C., van Harn, J., Gunnink, H., Hindle, V. A., and Lourens, A. (2012). Footpad dermatitis in Dutch broiler flocks: prevalence and factors of influence. Poult. Sci. 91, 1569-1574. doi: 10.3382/ps.2012-02156

Decina, C., Berke, O., Van Staaveren, N., Baes, C. F., Widowski, T. M., and Harlander-Matauschek, A. (2019). A cross-sectional study on feather cover damage in Canadian laying hens in non-cage housing systems. BMC Vet. Res. 15, 1-9. doi: 10.1186/s12917-019-2168-2

Đuki, M., Bjedov, S., Žiki, D., Peri, L., and Miloševi, N. (2016). Effect of straw size and microbial amendment of litter on certain litter quality parameters, ammonia emission, and footpad dermatitis in broilers. Arch. Anim. Breed. 59, 131-137. doi: 10.5194/aab-59-131-2016

Ekstrand, C., and Algers, B. (1997). Rearing conditions and foot-pad dermatitis in Swedish turkey poults. Acta Vet. Scand. 38, 167-174. doi: 10.1186/BF03548496

Ekstrand, C., Algers, B., and Svedberg, J. (1997). Rearing conditions and footpad dermatitis in Swedish broiler chickens. Prev. Vet. Med. 31, 167-174. doi: 10.1016/S0167-5877(96)01145-2

Erasmus, M. A. (2017a). A review of the effects of stocking density on Turkey behavior, welfare, and productivity. Poult. Sci. 96, 2540-2545. doi: $10.3382 / \mathrm{ps} / \mathrm{pex} 075$

Erasmus, M. A. (2017b). "Welfare issues in turkey production," in Advances in Poultry Welfare Food Science, Technology and Nutrition, ed J. A. Mench (Elsevier), 263-291. doi: 10.1016/B978-0-08-100915-4.00013-0
(Industry) and CB (Academic)]. The authors would also like to acknowledge NSERC and Hybrid Turkeys for financial support.

\section{ACKNOWLEDGMENTS}

The authors would like to acknowledge the turkey farmers and personnel who participated in this study. Additionally, the authors would like to thank graduate student Sarah Adams, poultry veterinarian Dr. Lloyd Weber and family, feed company representative Caitlin Woolcott, genetic company representatives Jeff Mohr and Gary Hall, and the Turkey Farmers of Canada (TFC) for their input on the survey development.

Ferket, P. R. (1995). "Flushing syndrome in commercial turkeys during the grow-out stage," in Smithkline Beecham Pacesetter Conference. National Turkey Federation Annual Meeting, 5-14.

Freihold, D., Bartels, T., Bergmann, S., Berk, J., Deerberg, F., Dressel, A., et al. (2019). Investigation of the prevalence and severity of foot pad dermatitis at the slaughterhouse in fattening turkeys reared in organic production systems in Germany. Poult. Sci. 98, 1559-1567. doi: 10.3382/ps/pey473

Grimes, J. L., Smith, J., and Williams, C. M. (2002). Some alternative litter materials used for growing broilers and turkeys. Worlds Poult. Sci. J. 58, 515-526. doi: 10.1079/WPS20020037

Hawke, F., and Burns, J. (2009). Understanding the nature and mechanism of foot pain. J. Foot Ankle Res. 2, 1-11. doi: 10.1186/1757-1146-2-1

Hocking, P. M., and Wu, K. (2013). Traditional and commercial turkeys show similar susceptibility to foot pad dermatitis and behavioural evidence of pain. Br. Poult. Sci. 54, 281-288. doi: 10.1080/00071668.2013.781 265

Hybrid Turkeys (2020). Technical Guide for Hybrid Turkeys Commercial Products. Kitchener, ON.

Knierim, U., Andersson, R., Keppler, C., Petermann, S., Rauch, E., Spindler, B., et al. (2016). "Mastputen," in Tierschutzindikatoren: Leitfaden fur die Praxis Geflugel, 1st Edn, (Darmstadt: KTBL), 41-57.

Krautwald-Junghanns, M.-E., Ellerich, R., Mitterer-Istyagin, H., Ludewig, M., Fehlhaber, K., Schuster, E., et al. (2011). Examinations on the prevalence of footpad lesions and breast skin lesions in British United Turkeys Big 6 fattening turkeys in Germany. Part I: prevalence of footpad lesions. Poult Sci. 90, 555-560. doi: 10.3382/ps.2010-01046

Krautwald-Junghanns, M. E., Bergmann, S., Erhard, M. H., Fehlhaber, K., Hübel, J., Ludewig, M., et al. (2013). Impact of selected factors on the occurrence of contact dermatitis in turkeys on commercial farms in Germany. Animals 3, 608-628. doi: 10.3390/ani3030608

Manangi, M. K., Vazquez-Añon, M., Richards, J. D., Carter, S., Buresh, R. E., and Christensen, K. D. (2012). Impact of feeding lower levels of chelated trace minerals versus industry levels of inorganic trace minerals on broiler performance, yield, footpad health, and litter mineral concentration. J. Appl. Poult. Res. 21, 881-890. doi: 10.3382/japr.2012-00531

Martland, M. F. (1984). Wet litter as a cause of plantar pododermatitis, leading to foot ulceration and lameness in fattening turkeys. Avian Pathol. 13, 241-252. doi: 10.1080/03079458408418528

Martrenchar, A., Boilletot, E., Huonnic, D., and Pol, F. (2002). Risk factors for footpad dermatitis in chicken and turkey broilers in France. Prev. Vet. Med. 52, 213-226. doi: 10.1016/S0167-5877(01)00259-8

Mayne, R. K. (2005). A review of the aetiology and possible causative factors of foot pad dermatitis in growing turkeys and broilers. Worlds Poult. Sci. J. 61, 256-267. doi: 10.1079/WPS200458

Mayne, R. K., Else, R. W., and Hocking, P. M. (2007). High litter moisture alone is sufficient to cause footpad dermatitis in growing turkeys. Br. Poult. Sci. 48, 538-545. doi: 10.1080/00071660701573045

Mitterer-Istyagin, H., Ludewig, M., Bartels, T., Krautwald-Junghanns, M. E., Ellerich, R., Schuster, E., et al. (2011). Examinations on the prevalence of footpad lesions and breast skin lesions in B.U.T. Big 6 fattening turkeys in 
Germany. Part II: prevalence of breast skin lesions (breast buttons and breast blisters). Poult. Sci. 90, 775-780. doi: 10.3382/ps.2010-01142

Monckton, V., van Staaveren, N., Baes, C. F., Balzani, A., Kwon, I. Y., McBride, P., et al. (2020). Are turkeys (Meleagris gallopavo) motivated to avoid excretasoiled substrate? Animals 10, 1-15. doi: 10.3390/ani10112015

Muir, G. D., Gosline, J. M., and Steeves, J. D. (1996). Ontogeny of bipedal locomotion: walking and running in the chick. J. Physiol. 493, 589-601. doi: 10.1113/jphysiol.1996.sp021406

National Farm Animal Care Council (2016). Code of Practice for the Care and Handling of Hatching Eggs, Breeders, Chickens, and Turkeys. Available online at: www.chep-poic.ca (accessed October 16, 2020).

Patterson, P. H., Sunde, M. L., and Pimentel, J. L. (1989). Water consumption and fecal moisture of laying hens fed wheat middlings and corn-soybean-alfalfa meal diets. Poult. Sci. 68, 830-832. doi: 10.3382/ps.0680830

Rucker, R. B., Kosonen, T., Clegg, M. S., Mitchell, A. E., Rucker, B. R., UriuHare, J. Y., et al. (1998). Copper, lysyl oxidase, and extracellular matrix protein cross-linking. Am. J. Clin. Nutr. 67, 996-1002. doi: 10.1093/ajcn/67.5.996S

Rushen, J., and Passillé, A. M. B. de. (1992). The scientific assessment of the impact of housing on animal welfare: a critical review. Can. J. Anim. Sci. 72, 721-743. doi: 10.4141/cjas92-085

Saeed, M., Babazadeh, D., Naveed, M., Arain, M. A., Hassan, F. U., and Chao, S. (2017). Reconsidering betaine as a natural anti-heat stress agent in poultry industry: a review. Trop. Anim. Health Prod. 49, 1329-1338. doi: $10.1007 / \mathrm{s} 11250-017-1355-\mathrm{Z}$

Shepherd, E. M., and Fairchild, B. D. (2010). Footpad dermatitis in poultry. Poult. Sci. 89, 2043-2051. doi: 10.3382/ps.2010-00770

Sinclair, A., Wyneken, C. W., Veldkamp, T., Vinco, L. J., and Hocking, P. M. (2015). Behavioural assessment of pain in commercial turkeys (Meleagris gallopavo) with foot pad dermatitis. Br. Poult. Sci. 56:1077204. doi: 10.1080/00071668.2015.1077204

Terčič, D., Žolger, M., and Pestotnik, M. (2015). Effect of different litter materials on foot pad dermatitis, hock burn and feather coverage in broiler chickens. Acta Agric. Slov. 106, 97-101. doi: 10.14720/aas.2015.106.2.5

Tullo, E., Fontana, I., Peña Fernandez, A., Vranken, E., Norton, T., Berckmans, D., et al. (2017). Association between environmental predisposing risk factors and leg disorders in broiler chickens. J. Anim. Sci. 95, 1512-1520. doi: $10.2527 /$ jas 2016.1257

Turkey Farmers of Canada (2018). On-Farm Programs. Missisauga, ON.

van Staaveren, N., Leishman, E., Adams, S., Wood, B., Harlander-Matauschek, A., and Baes, C. (2020). Housing and management of Turkey Flocks in Canada. Animals 10:1159. doi: 10.3390/ani10071159

Ward, P. L., Wohlt, J. E., Zajac, P. K., and Cooper, K. R. (2000). Chemical and physical properties of processed newspaper compared to wheat straw and wood shavings as animal bedding. J. Dairy Sci. 83, 359-367. doi: 10.3168/jds.S0022-0302(00)74887-9
Watanabe, T. T. N., Lolli, S., Ferrari, L., and Ferrante, V. (2013). Review of the physiological and pathological welfare indicators applied in turkeys (Meleagris gallopavo). Biotechnol. Anim. Husb. 29, 727-740. doi: 10.2298/BAH1304727W

Weber Wyneken, C. W., Sinclair, A., Veldkamp, T., Vinco, L. J., and Hocking, P. M. (2015). Footpad dermatitis and pain assessment in turkey poults using analgesia and objective gait analysis. Br. Poult. Sci. 56, 522-530. doi: 10.1080/00071668.2015.1077203

Windhorst, H. W. (2006). Changing regional patterns of turkey production and turkey meat trade. Worlds Poult. Sci. J. 62:200487. doi: 10.1079/WPS200487

Wood, B. J., and Willems, O. W. (2014). "Selection for improved efficiency in poultry, progress to date and challenges for the future," in Procceedings 10th World Congr Genet Appl to Livest Prod Sel, (Vancouver, BC), 5.

Youssef, I. M. I., Beineke, A., Rohn, K., and Kamphues, J. (2011). Effects of litter quality (moisture, ammonia, uric acid) on development and severity of foot pad dermatitis in growing turkeys. Avian Dis. 55, 51-58. doi: 10.1637/9495-081010-Reg.1

Zhao, J., Shirley, R. B., Vazquez-Anon, M., Dibner, J. J., Richards, J. D., Fisher, P., et al. (2010). Effects of chelated trace minerals on growth performance, breast meat yield, and footpad health in commercial meat broilers. J. Appl. Poult. Res. 19, 365-372. doi: 10.3382/japr.2009-00020

Conflict of Interest: BW was an employee of Hybrid Turkeys at the time of the study. Hybrid turkeys disseminated an invitation to voluntarily participate in the study among its farm managers. The funders had no further role in the design of the study and collection, analysis, and interpretation of data and in writing the manuscript.

The remaining authors declare that the research was conducted in the absence of any commercial or financial relationships that could be construed as a potential conflict of interest.

Publisher's Note: All claims expressed in this article are solely those of the authors and do not necessarily represent those of their affiliated organizations, or those of the publisher, the editors and the reviewers. Any product that may be evaluated in this article, or claim that may be made by its manufacturer, is not guaranteed or endorsed by the publisher.

Copyright (C) 2021 Leishman, van Staaveren, Osborne, Wood, Baes and HarlanderMatauschek. This is an open-access article distributed under the terms of the Creative Commons Attribution License (CC BY). The use, distribution or reproduction in other forums is permitted, provided the original author(s) and the copyright owner(s) are credited and that the original publication in this journal is cited, in accordance with accepted academic practice. No use, distribution or reproduction is permitted which does not comply with these terms. 